\title{
The unrest of the San Miguel volcano (EI Salvador, Central America): installation of the monitoring network and observed volcano-tectonic ground deformation
}

\author{
Alessandro Bonforte ${ }^{1}$, Douglas Antonio Hernandez ${ }^{2}$, Eduardo Gutiérrez $^{2}$, Louis Handal ${ }^{2}$, Cecilia Polío $^{2}$, \\ Salvatore Rapisarda ${ }^{1}$, and Piergiorgio Scarlato ${ }^{3}$ \\ ${ }^{1}$ Istituto Nazionale di Geofisica e Vulcanologia, Sezione di Catania - Osservatorio Etneo, Piazza Roma 2, 95125 Catania, Italy \\ ${ }^{2}$ Ministerio de Medio Ambiente y Recursos Naturales, Kilómetro 5 1/2 Carretera a Santa Tecla, Calle y Colonia Las \\ Mercedes, San Salvador, EL Salvador \\ ${ }^{3}$ Istituto Nazionale di Geofisica e Vulcanologia, Sezione di Sismologia e Tettonofisica, Via di Vigna Murata 605, \\ 00143 Roma, Italy
}

Correspondence to: Alessandro Bonforte (alessandro.bonforte@ingv.it)

Received: 1 August 2015 - Published in Nat. Hazards Earth Syst. Sci. Discuss.: 9 October 2015

Revised: 8 February 2016 - Accepted: 17 February 2016 - Published: 3 August 2016

\begin{abstract}
On 29 December 2013, the Chaparrastique volcano in El Salvador, close to the town of San Miguel, erupted suddenly with explosive force, forming a column more than $9 \mathrm{~km}$ high and projecting ballistic projectiles as far as $3 \mathrm{~km}$ away. Pyroclastic density currents flowed to the north-northwest side of the volcano, while tephras were dispersed northwest and north-northeast. This sudden eruption prompted the local Ministry of Environment to request cooperation with Italian scientists in order to improve the monitoring of the volcano during this unrest. A joint force, made up of an Italian team from the Istituto Nazionale di Geofisica e Vulcanologia and a local team from the Ministerio de Medio Ambiente y Recursos Naturales, was organized to enhance the volcanological, geophysical and geochemical monitoring system to study the evolution of the phenomenon during the crisis. The joint team quickly installed a multiparametric mobile network comprising seismic, geodetic and geochemical sensors (designed to cover all the volcano flanks from the lowest to the highest possible altitudes) and a thermal camera. To simplify the logistics for a rapid installation and for security reasons, some sensors were colocated into multiparametric stations. Here, we describe the prompt design and installation of the geodetic monitoring network, the processing and results. The installation of a new ground deformation network can be considered an important result by itself, while the detection of some crucial deforming areas is very signif-
\end{abstract}

icant information, useful for dealing with future threats and for further studies on this poorly monitored volcano.

\section{Introduction}

The San Miguel volcano, also known as Chaparrastique, is a symmetrical stratovolcano, which reaches $2130 \mathrm{~m}$ a.s.l. (above sea level). Its summit crater measures $800 \mathrm{~m}$ in diameter and $340 \mathrm{~m}$ in depth. The El Pacayal volcano (currently inactive) is located $6 \mathrm{~km} \mathrm{NW}$ from the San Miguel edifice (Fig. 1).

Geographically, it is located in the department of San Miguel, in the eastern part of El Salvador, at coordinates $13.43143^{\circ} \mathrm{N}$ and $88.271468^{\circ} \mathrm{W}$. The entire edifice belongs to the municipalities of San Miguel, Quelepa, Moncagua, Chinameca, San Jorge, San Rafael Oriente and El Tránsito.

Geologically, it belongs to the quaternary period (probably with an age of about 50000 years) and is mainly made up of basaltic and andesitic rocks. However, the stratigraphy of the volcano is intercalated with Plinian acid deposits (dacite and rhyodacite) of the El Pacayal volcano. Lava flows and mafic scoria emitted through lateral fissures (Escobar et al., 2004) are evident on the flanks of the volcano; the occurrence of such lateral eruptions increases the hazard for the numer- 


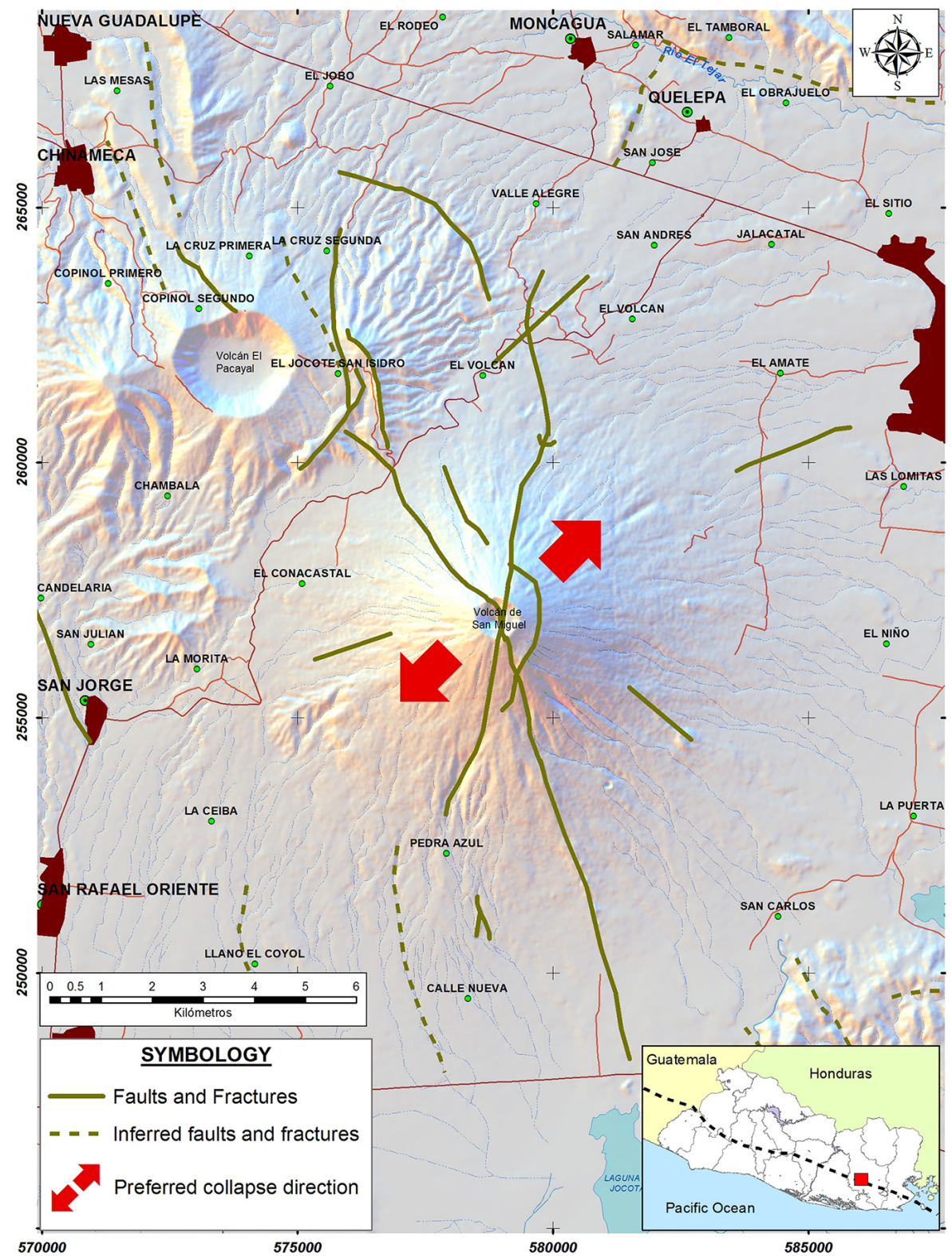

Figure 1. Tectonics and geodynamics of the San Miguel volcano. The SMFZ is identified with A. The triangles show the installed seismometers. The circles mark the historical eruptions. Red arrows indicate the possible collapse directions. Taken from Schiek (2008).

ous people living on the volcano slopes and requiring a more dense monitoring all around its flanks.

Tectonically, the volcano is located in the eastern segment of the Central Graben of the country, and it is crossed by local faults with a predominant NW-SE direction (see Fig. 1). A huge fault is located to the north, $10 \mathrm{~km}$ away from the volcano, with a predominant $\mathrm{E}-\mathrm{W}$ direction, and it defines the forearc segment that interacts directly with the Cocos Plate. This fault is locally called the "El Salvador fault zone (ESFZ)". The forearc sliver shows a regional movement relative to the Caribbean plate towards the northwest, with an average speed of about $15 \pm 2 \mathrm{~mm}$ per year (Correa-Mora et al., 2009; Alvarado et al., 2011).

According to the Ministry of Environment and Natural Resources of El Salvador, around 5000 people living on the northwestern flank of the volcano are those most exposed to the volcanic hazard.

In the last 1500 years, the San Miguel volcano has undergone at least 25 small eruptions, being the most active volcano in the Salvadorean volcanic chain. Since 1867, there have been at least 15 explosive eruptions through the central crater (MARN, 2014). The volcanic explosivity index (VEI) estimated for that period has been set between 1 and 2 


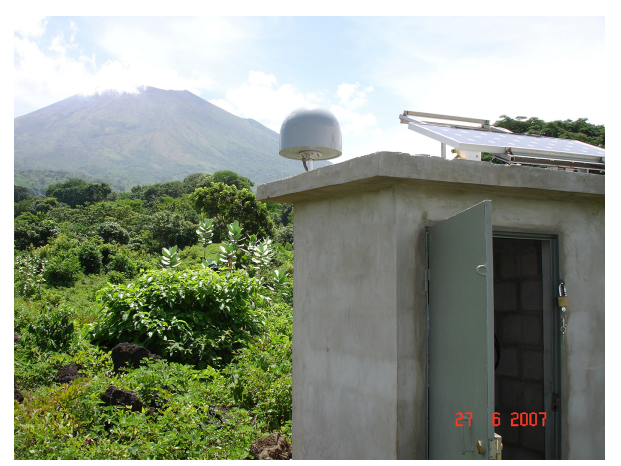

Figure 2. GPS hut located close to the San Miguel volcano (VMIG).

(Schiek, 2008). The latest eruption occurred on 29 December 2013, when the volcano ejected a moderate volume of ashes and ballistics through the central crater, damaging several crops on the northern flank and prompting the people working there to take flight.

It is also important to note that the volcanic hazard of San Miguel is not confined to an eruptive episode involving lava and pyroclastic flows, gas emissions, etc., but the instability of the steep slopes also create suitable conditions for generating landslides, debris flows or mudslides. The NW, NE, SE, S and SW flanks show vestiges of such historical events. At present, the drainage system of the NW sector towards Las Placitas, La Piedra, Lotificación Hercules and Caserío La Cruz are being affected by this phenomenon, which increases the hazard and needs to be monitored, especially during unrest periods.

The aim of this paper is to describe the international cooperation which formed to improve monitoring during the crisis, the design and installation of the multiparametric network, the processing of GPS data and the observed ground deformation. This is the very first case in which this volcano will have such a complete monitoring system. In particular, the geodetic network installed is available for future studies and crisis management, and the ground deformation analyses reported here provide useful first insights into defining the deforming areas of the volcano, where attention could be concentrated for monitoring, and their possible significance.

\section{Background}

Ground deformation at the San Miguel volcano was studied by Schiek (2008), by applying radar interferometry. Earthquake activity was also studied due to a network of six broadband stations around the volcano. The management of the seismic network was carried out by the Servicio Nacional de Estudios Territoriales (SNET) of the Ministry of Environment and Natural Resources of El Salvador (Ministerio de Medio Ambiente y Recursos Naturales, MARN). The equipment recorded continuously from March 2007 to January 2008. The SAR data were available for the period from

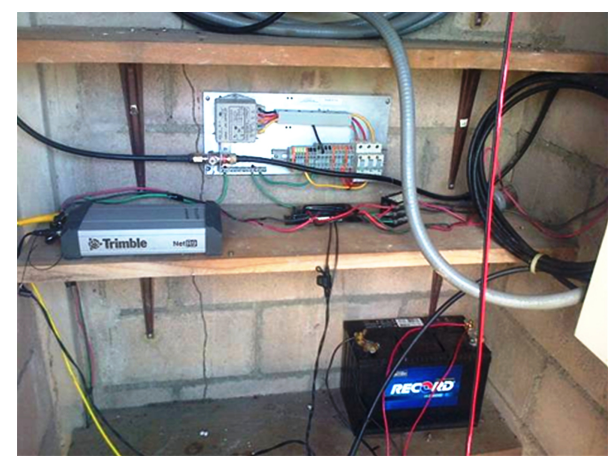

Figure 3. GPS receiver installed at the San Miguel volcano (VMIG).

February 2007 to January 2008. The study suggested that the main volcanic activity occurs along a fault crossing the crater in a north-south direction, known as the San Miguel fracture zone (SMFZ, see Fig. 1). Schiek (2008) measured a long-term succession of ground inflation and subsidence during that period, recording a maximum inflation of $6 \pm 0.1 \mathrm{~cm}$ before mid-October 2007. After this period a maximum deflation of $4 \pm 0.1 \mathrm{~cm}$ was verified until January 2008. The seismic data were used to model the subsurface geometry of SMFZ, determining that during the inflation period there was an excess of pressure of about $0.05 \mathrm{MPa}$; for the deflation, a value of about $-0.05 \mathrm{MPa}$ was estimated.

\section{Continuous GPS station at the San Miguel volcano}

During 2007 and 2008, in the framework of a long-term research project by MARN and the University of Wisconsin, Madison on earthquakes and tectonics, continuous GPS stations were installed close to the volcanoes of Santa Ana, San Salvador and San Miguel. In the particular case of San Miguel, the GPS station (named VMIG) was installed on 27 June 2007, in the Piedra Azul village on the southwestern flank of the volcano (Fig. 2). The deployed equipment comprised Trimble dual-frequency receivers and zephyr geodetic antennas, configured to acquire data every $30 \mathrm{~s}$ (Fig. 3).

\section{The 29 December 2013 eruption}

At 10:30 (LT = UTC-6) on Sunday 29 December 2013, the Chaparrastique volcano suddenly erupted, forming a column that reached an height of $9.74 \mathrm{~km}$ a.s.l. and ejecting ballistic projectiles as far as $34 \mathrm{~km}$ away (Fig. 4). Pyroclastic density currents flowed onto the north-northwestern side of the upper third of the volcanic edifice, and tephras were deposited toward the northwest and north-northeast areas. The pyroclastic currents and fallout heavily damaged coffee plantations on the slopes of the volcano and frightened many people working there, forcing them to flee from the dense and 


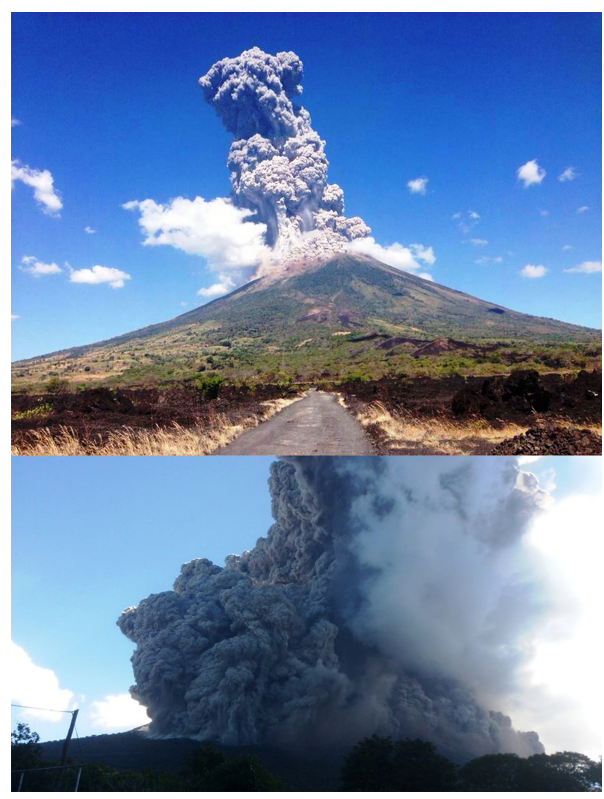

Figure 4. Images of the 29 December 2013 eruption.

suffocating ash cloud. The intense part of the eruptive phase lasted about $90 \mathrm{~min}$. After the unrest, the volcano continued degassing, emitting around $1100 \mathrm{tday}^{-1}$ of $\mathrm{SO}_{2}$ during the next 15 days. Changes in amplitude of volcanic tremor were observed during the 10 months following the eruption, and 15 small explosions were recorded until October 2014. These explosions reached a height of less than $1 \mathrm{~km}$, and tiny ashfall deposits (millimeter in thickness) on the slopes of the volcano were observed. In Fig. 5, a time series of the tremor amplitude (daily averages) and the volcanic activity recorded during the period investigated by GPS measurements on the new network is reported.

\section{New GPS network design and installation}

The ground deformation network was designed to cover the entire volcano from the lowest to the highest possible altitude in order to monitor not only the central part of the volcano but also its flanks for flank intrusions and/or slope stability.

The geodetic network consisted of 10 self-centering benchmarks of the same type usually installed on Mt. Etna in Italy (Puglisi and Bonforte, 2004; Bonforte and Puglisi, 2006); these benchmarks allow rapid installation and setup of the instrumentation and have a minimum impact. This type of benchmark enables setting up the station in less than a minute and even by personnel without any geodetic expertise. All geodetic benchmarks on and around Chaparrastique volcano were installed in 2 days, on 29 and 30 January.

The final configuration of the multiparametric network installed by the joint international team is reported in Fig. 6. The GPS instrumentation comprised 10 Trimble dualfrequency receivers, model 4700 , equipped with 4 Trim- ble Zephyr and 6 Leica AX1202GG antennas. Some GPS sensors, where possible, were colocated with already existing geophysical/geochemical stations (seismic, infrasound, gas plume for $\mathrm{CO}_{2} / \mathrm{SO}_{2}$ and $\mathrm{SO}_{2}$ flux and radiometric for measuring the volcanic plume temperature). Local personnel were also trained on how to manage, program, maintain and process the collected data to ensure the maximum efficiency and local autonomy in managing the ongoing crisis.

\section{Data acquisition and processing}

Initially, a single 4-day survey was planned, to then be repeated during the following months in order to measure the station displacements. However, due to the continuous tremor increase during measuring, we decided to keep all the GPS stations installed on the benchmarks in order to study the potential ground deformation accompanying the unrest episode. Due to the initial plans, data were stored locally in the memory of the sensors and were downloaded weekly by the MARN team. On the other hand, this allowed local personnel to routinely check the status of the stations which sometimes suffered power failures, reducing the data loss to periods of a few days at maximum. All GPS stations of this network were then removed at the end of April. Daily operation of the installed GPS stations and data availability is reported in Fig. 7.

Data from the Piedra Azul (VMIG, Fig. 6) permanent GPS station were added to the processing to increase the number of stations on and around the volcano. This station lies on the volcano flank and cannot be chosen as a reference but it can be used for monitoring the volcano deformation. In order to refer the ground motion to a stable reference frame external to the volcano, we added the data from the far GUAT (Guatemala City), MANA (Managua), SSIA (San Salvador), ELEN (S. Elena), CN22 (Las Penitas) and CN23 (Belize) ITRF stations to the processing. Considering the continuity of data acquisition at the stations, the small and slow expected deformation and the not very long time period investigated, which do not allow slow trends to be clearly visible above the daily noise level, we wanted to work for the most stable solution, reaching a compromise between the temporal resolution and the accuracy of the results. In fact, once final precise ephemerides were available weekly by IGS (International GNSS Service), each week of data was processed to achieve a unique coordinate for each station in the ITRF reference frame epoch 2014.1 (Altamimi et al., 2011). In this way, we obtained the most robust point solutions and were able also to overcome a sporadic lack of data that sometimes affected some stations for short periods (a couple of days); only during the second week were SSIA station data lacking for the entire processed period (2-8 February, GPS week 1778, see Fig. 7), while all other stations are continuously present in all weekly solutions with at least one $8 \mathrm{~h}$ measurement session. 


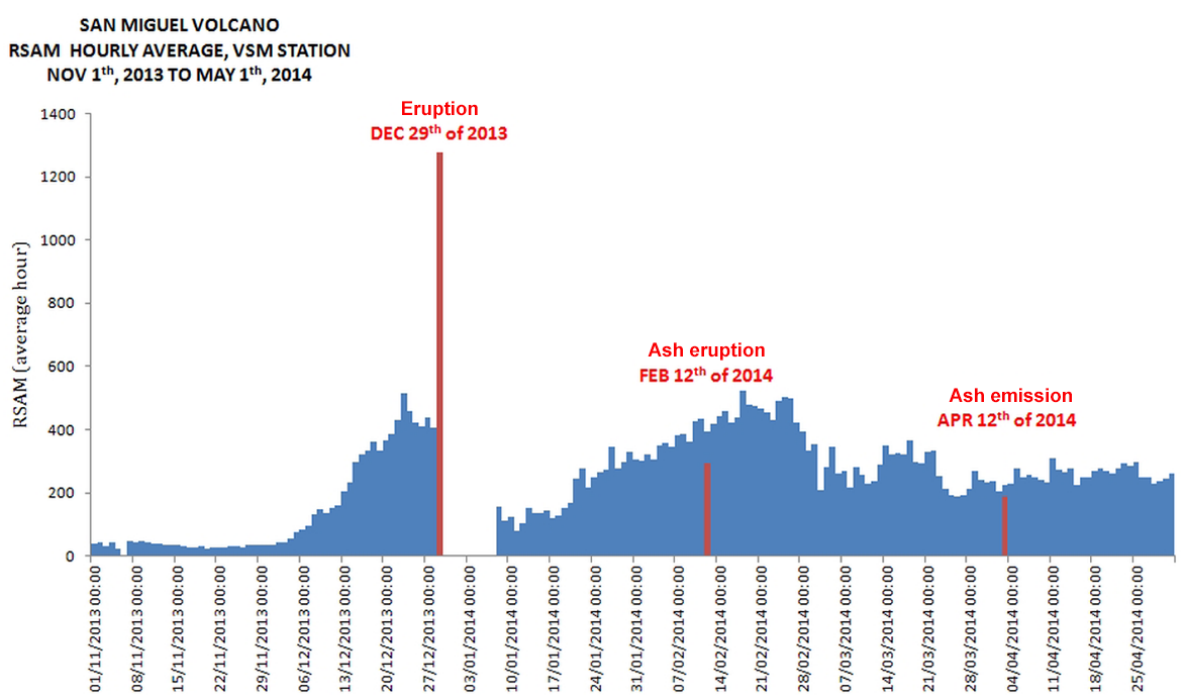

Figure 5. Eruption of 29 December 2013 and small explosions. The blue lines show the RSAM (Real-time Seismic Amplitude Measurement) behavior during 2014 and the first days of 2015. Units are in counts.

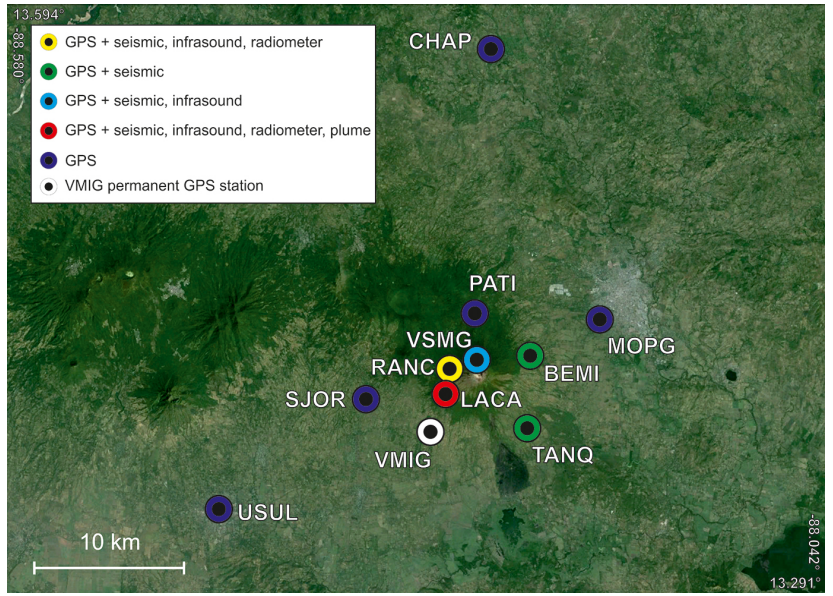

Figure 6. Map of the multiparametric network installed in January 2014.

The processing presented here was performed using the Trimble Business Center version 2.81, using the IGS final precise ephemeris and IGS absolute antenna calibration tables. Due to some anomalous interruptions in the data acquisitions, mainly owing to power failures, a first filter was applied and only baselines connecting stations with more than $8 \mathrm{~h}$ overlap were selected for processing. In this way, each processed network was made up of 17 stations and about 500 suitable baselines (Fig. 8). Each week of data, from GPS week 1778 to GPS week 1789, was processed as a whole and only fixed solutions were kept for the adjustment process; a first free (inner constraints) adjustment was performed in order to detect any noisy solution and then, after bad solutions were fixed or removed, a constrained adjustment was performed. Coordinates of the ITRF stations were fixed to their values in the ITRF08 frame at epoch 2014.1 (Altamimi et al., 2011). In this way, all station solutions on and around the volcano were referred to the same fixed frame and coordinate comparisons should reveal any local ground deformation within the ITRF reference and regional motion, following the approach of Bonforte and Guglielmino (2008).

Final $2 \sigma$ positioning errors in the station coordinates, resulting after each weekly final network adjustment, were around $2-3 \mathrm{~mm}$ for the horizontal components and $4-5 \mathrm{~mm}$ for the vertical one.

\section{Analysis of the ground deformation}

Here, we show and analyze the weekly solutions of each station installed on the San Miguel volcano. In Fig. 9, all the time series of the three components of motions are plotted for each station.

Starting from the analysis of the coordinates time series, in general there is no substantial motion at the stations during the investigated period. A vertical motion seems to characterize the first half of the period at most stations, followed by a more disturbed period, but the variations are often lower than the measurement errors.

Stations on the western flank appear to show a fluctuation in the horizontal components of motion just a few days after the tremor amplitude increase around the ash emission of 12 February 2014, roughly coinciding with the following steep decrease recorded from the end of January to the end of February. At the Lacayo (LACA in Fig. 6) and VMIG stations, on the southwestern side of the edifice, a slight general uplift could be recognized, more pronounced during the first half of the observed period. 


\begin{tabular}{|c|c|c|c|c|c|c|c|c|}
\hline & date & DOY & BEMI & CHAP & CN22 & CN23 & ELEN & GUAT \\
\hline & $30 \mathrm{Jan}$ & 30 & $x$ & & $x$ & & $x$ & $x$ \\
\hline & $31 \mathrm{Jan}$ & 31 & $x$ & & $x$ & & & $x$ \\
\hline & $1 \mathrm{Feb}$ & 32 & $x$ & & $x$ & & & \\
\hline & $2 \mathrm{Feb}$ & 33 & $x$ & & $x$ & & $x$ & $\mathrm{x}$ \\
\hline & $3 \mathrm{Feb}$ & 34 & $x$ & & $x$ & & $x$ & $x$ \\
\hline 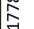 & $4 \mathrm{Feb}$ & 35 & & & $x$ & & $x$ & $x$ \\
\hline & $5 \mathrm{Feb}$ & 36 & & & $x$ & $x$ & $x$ & $x$ \\
\hline & $6 \mathrm{Feb}$ & 37 & & $x$ & $x$ & $x$ & $x$ & $x$ \\
\hline & $7 \mathrm{Feb}$ & 38 & $x$ & $x$ & $x$ & $x$ & $x$ & $x$ \\
\hline & $8 \mathrm{Feb}$ & 39 & & $x$ & $x$ & $x$ & $x$ & $x$ \\
\hline & $9 \mathrm{Feb}$ & 40 & & $x$ & $x$ & $x$ & $x$ & $x$ \\
\hline & $10 \mathrm{Feb}$ & 41 & $x$ & $x$ & $x$ & $x$ & $x$ & $x$ \\
\hline I & $11 \mathrm{Feb}$ & 42 & $x$ & $x$ & $x$ & $x$ & $x$ & $x$ \\
\hline & $12 \mathrm{Feb}$ & 43 & $x$ & $x$ & $x$ & $x$ & $x$ & $x$ \\
\hline$\sum_{3}^{\circ}$ & $13 \mathrm{Feb}$ & 44 & $x$ & $x$ & $x$ & $x$ & $x$ & $x$ \\
\hline & $14 \mathrm{Feb}$ & 45 & $x$ & $x$ & $x$ & $x$ & $x$ & $x$ \\
\hline & $15 \mathrm{Feb}$ & 46 & $x$ & $x$ & $x$ & $x$ & $x$ & $x$ \\
\hline & $16 \mathrm{Feb}$ & 47 & $x$ & $x$ & $x$ & $x$ & $x$ & $x$ \\
\hline & $17 \mathrm{Feb}$ & 48 & $x$ & $x$ & $x$ & $x$ & $x$ & $x$ \\
\hline 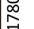 & $18 \mathrm{Feb}$ & 49 & & $x$ & $x$ & $x$ & & $x$ \\
\hline \% & $19 \mathrm{Feb}$ & 50 & $x$ & $x$ & $x$ & $x$ & & $x$ \\
\hline 3ัँ & $20 \mathrm{Feb}$ & 51 & $x$ & $x$ & $x$ & $x$ & $x$ & $x$ \\
\hline & $21 \mathrm{Feb}$ & 52 & $x$ & $x$ & $x$ & $x$ & $x$ & $x$ \\
\hline & $22 \mathrm{Feb}$ & 53 & $x$ & $x$ & $x$ & $x$ & $x$ & $x$ \\
\hline & $23 \mathrm{Feb}$ & 54 & $x$ & $x$ & $x$ & $x$ & & $x$ \\
\hline & $24 \mathrm{Feb}$ & 55 & $x$ & $x$ & $x$ & $x$ & & $x$ \\
\hline 恶 & $25 \mathrm{Feb}$ & 56 & $x$ & $x$ & $x$ & $x$ & & $x$ \\
\hline & $26 \mathrm{Feb}$ & 57 & $x$ & $x$ & $x$ & $x$ & $x$ & $x$ \\
\hline ֻूँ & $27 \mathrm{Feb}$ & 58 & $x$ & $x$ & $x$ & $x$ & $x$ & $x$ \\
\hline & $28 \mathrm{Feb}$ & 59 & $x$ & $x$ & $x$ & $x$ & $x$ & $x$ \\
\hline & $1 \mathrm{Mar}$ & 60 & $x$ & $x$ & $x$ & $x$ & $x$ & $x$ \\
\hline & $2 \mathrm{Mar}$ & 61 & $x$ & $x$ & $x$ & $x$ & $x$ & $x$ \\
\hline & $3 \mathrm{Mar}$ & 62 & $x$ & $x$ & $x$ & $x$ & $x$ & $x$ \\
\hline$\stackrel{\infty}{\infty}$ & $4 \mathrm{Mar}$ & 63 & $x$ & $x$ & $x$ & $x$ & $x$ & $x$ \\
\hline$\frac{2}{2}$ & $5 \mathrm{Mar}$ & 64 & $x$ & $x$ & $x$ & $x$ & $x$ & $x$ \\
\hline$\sum_{\text {sँ }}$ & 6 Mar & 65 & $x$ & $x$ & $x$ & $x$ & $x$ & $x$ \\
\hline & 7 Mar & 66 & $x$ & $x$ & $x$ & $x$ & $x$ & $x$ \\
\hline & $8 \mathrm{Mar}$ & 67 & $x$ & $x$ & $x$ & $x$ & $x$ & $x$ \\
\hline & 9 Mar & $\begin{array}{ll}68 \\
\end{array}$ & $x$ & $x$ & $x$ & $x$ & $x$ & $x$ \\
\hline & $10 \mathrm{Mar}$ & 69 & $x$ & $x$ & $x$ & $x$ & & $x$ \\
\hline$\stackrel{\infty}{-\infty}$ & $11 \mathrm{Mar}$ & 70 & $x$ & $x$ & $x$ & $x$ & $x$ & $x$ \\
\hline$\frac{\sqrt{3}}{\alpha}$ & $12 \mathrm{Mar}$ & 71 & $x$ & $x$ & $x$ & $x$ & $x$ & $x$ \\
\hline ֻัँ & $13 \mathrm{Mar}$ & 72 & $x$ & $x$ & $x$ & $x$ & $x$ & $x$ \\
\hline & $14 \mathrm{Mar}$ & 73 & $x$ & $x$ & $x$ & $x$ & $x$ & $x$ \\
\hline & $15 \mathrm{Mar}$ & 74 & $x$ & $x$ & $x$ & $x$ & $x$ & $x$ \\
\hline & $16 \mathrm{Mar}$ & 75 & $x$ & $x$ & $x$ & $x$ & $x$ & $x$ \\
\hline & $17 \mathrm{Mar}$ & 76 & $x$ & $x$ & $x$ & $x$ & $x$ & $x$ \\
\hline$\infty$ & $18 \mathrm{Mar}$ & 77 & $x$ & $x$ & $x$ & $x$ & $x$ & $x$ \\
\hline$\frac{\theta}{9}$ & $19 \mathrm{Mar}$ & 78 & $x$ & $x$ & $x$ & $x$ & $x$ & $x$ \\
\hline šँ & $20 \mathrm{Mar}$ & 79 & $x$ & $x$ & $x$ & $x$ & $x$ & $x$ \\
\hline & $21 \mathrm{Mar}$ & 80 & $x$ & $x$ & $x$ & $x$ & $x$ & $x$ \\
\hline & $22 \mathrm{Mar}$ & 81 & $x$ & $x$ & $x$ & $x$ & & $x$ \\
\hline & $23 \mathrm{Mar}$ & 82 & $x$ & $x$ & $x$ & $x$ & $x$ & $x$ \\
\hline & $24 \mathrm{Mar}$ & 83 & $x$ & $x$ & $x$ & $x$ & $x$ & $x$ \\
\hline$\infty$ & $25 \mathrm{Mar}$ & 84 & $x$ & $x$ & $x$ & $x$ & $x$ & $x$ \\
\hline$\frac{1}{2}$ & $26 \mathrm{Mar}$ & 85 & $x$ & $x$ & $x$ & $x$ & $x$ & $x$ \\
\hline ڤัँ & $27 \mathrm{Mar}$ & 86 & $x$ & $x$ & $x$ & $x$ & $x$ & $x$ \\
\hline & $28 \mathrm{Mar}$ & 87 & $x$ & $x$ & $x$ & $x$ & $x$ & $x$ \\
\hline & $29 \mathrm{Mar}$ & 88 & $x$ & $x$ & $x$ & $x$ & $x$ & $x$ \\
\hline & $30 \mathrm{Mar}$ & 89 & $x$ & $x$ & $x$ & $x$ & $x$ & $x$ \\
\hline & $31 \mathrm{Mar}$ & 90 & $x$ & $x$ & $x$ & $x$ & & $x$ \\
\hline 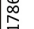 & $1 \mathrm{Apr}$ & 91 & $x$ & $x$ & $x$ & $x$ & & $x$ \\
\hline$\frac{7}{2}$ & $2 A p r$ & 92 & $x$ & $x$ & $x$ & $x$ & $x$ & $x$ \\
\hline$\sum_{3}^{\circ}$ & $3 \mathrm{Apr}$ & 93 & $x$ & $x$ & $x$ & $x$ & $x$ & $x$ \\
\hline & $4 \mathrm{Apr}$ & 94 & $x$ & $x$ & $x$ & $x$ & $x$ & $x$ \\
\hline & 5 Apr & 95 & $x$ & $x$ & $x$ & $x$ & $x$ & $x$ \\
\hline & $6 \mathrm{Apr}$ & 96 & $x$ & $x$ & $x$ & $x$ & $x$ & $x$ \\
\hline & $7 \mathrm{Apr}$ & 97 & $x$ & $x$ & $x$ & $x$ & $x$ & $x$ \\
\hline$\infty$ & $8 \mathrm{Apr}$ & 98 & $x$ & $x$ & $x$ & $x$ & $x$ & $x$ \\
\hline $\overrightarrow{\breve{v}}$ & $9 \mathrm{Apr}$ & 99 & $x$ & $x$ & $x$ & $x$ & $x$ & $x$ \\
\hline 乡ँ & $10 \mathrm{Apr}$ & 100 & $x$ & $x$ & $x$ & $x$ & $x$ & $x$ \\
\hline & $11 \mathrm{Apr}$ & 101 & $x$ & $x$ & $x$ & $x$ & $x$ & $x$ \\
\hline & $12 \mathrm{Apr}$ & 102 & $x$ & $x$ & $x$ & $x$ & $x$ & $x$ \\
\hline & $13 \mathrm{Apr}$ & 103 & $x$ & $x$ & $x$ & $x$ & $x$ & $x$ \\
\hline & $14 \mathrm{Apr}$ & 104 & $x$ & $x$ & $x$ & $x$ & $x$ & $x$ \\
\hline 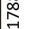 & $15 \mathrm{Apr}$ & 105 & $x$ & $x$ & $x$ & $x$ & $x$ & $x$ \\
\hline & $16 \mathrm{Apr}$ & 106 & $x$ & $x$ & $x$ & $x$ & $\mathrm{x}$ & $x$ \\
\hline 3 & $17 \mathrm{Apr}$ & 107 & $x$ & $x$ & $x$ & $x$ & $x$ & $x$ \\
\hline & $18 \mathrm{Apr}$ & 108 & $x$ & $x$ & $x$ & $x$ & $x$ & $x$ \\
\hline & $19 \mathrm{Apr}$ & 109 & $x$ & $x$ & $x$ & $x$ & $x$ & $x$ \\
\hline & $20 \mathrm{Apr}$ & 110 & $x$ & $x$ & $x$ & $x$ & $x$ & $x$ \\
\hline & $21 \mathrm{Apr}$ & 111 & $x$ & $x$ & $x$ & $x$ & $x$ & $x$ \\
\hline 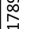 & $22 \mathrm{Apr}$ & 112 & $x$ & $x$ & $x$ & $x$ & $x$ & $x$ \\
\hline & $23 \mathrm{Apr}$ & 113 & $x$ & $x$ & $x$ & $x$ & $x$ & $x$ \\
\hline$\sum_{3}^{\circ}$ & $24 \mathrm{Apr}$ & 114 & $x$ & $x$ & $x$ & $x$ & $x$ & $x$ \\
\hline & $25 \mathrm{Apr}$ & 115 & $x$ & $x$ & $x$ & $x$ & $x$ & $x$ \\
\hline & $26 \mathrm{Apr}$ & 116 & $x$ & $x$ & $x$ & $x$ & $x$ & $x$ \\
\hline & $27 \mathrm{Apr}$ & 117 & $x$ & $x$ & & & & \\
\hline & $28 \mathrm{Apr}$ & 118 & $x$ & $x$ & & & & \\
\hline
\end{tabular}

Figure 7. Continuity of data acquisition at the GPS stations used for the weekly processing. 

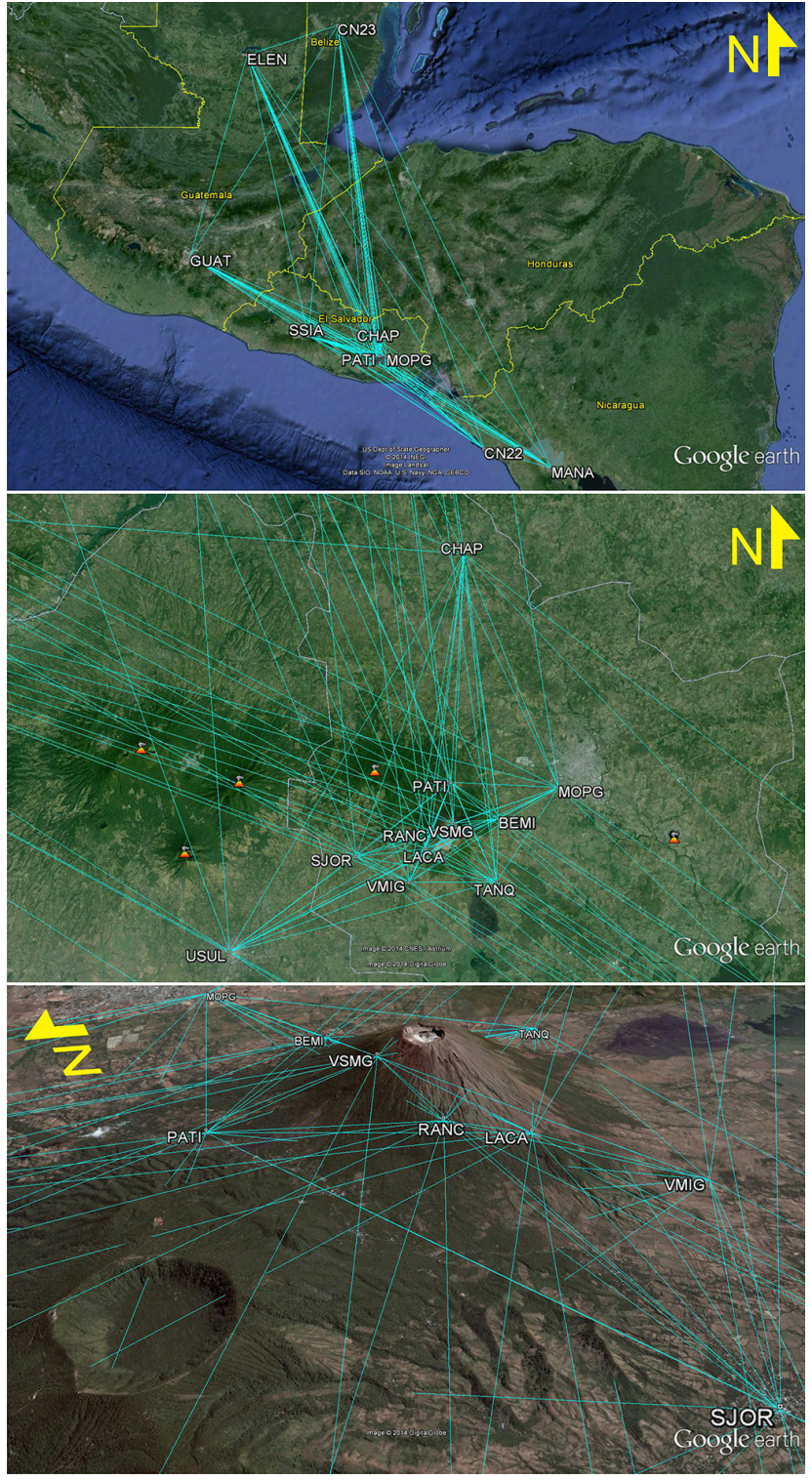

Figure 8. GPS network and baselines processed weekly for this work, from regional to local scale.

Deformations are often very little and can be masked by general network noises or, even worse, noise can simulate fake deformation that can be wrongly interpreted. In order to reduce the effects of common fluctuations of the positions, for example, due to reference system or atmospheric noise, the distance variations between station pairs were calculated and plotted, taking into account only the horizontal components in order to reduce the noise. Baseline analysis is often a better choice for monitoring volcanoes, in order to detect intrusions or inflation/deflation dynamics producing little and local deformation. In this way, the extension/contraction of different parts of the volcano can be analyzed with greater accuracy. The most interesting feature from this analysis at the San Miguel volcano is the detection of different areas of the volcano behaving differently in response to different dynamics.

The eastern side of the volcano, in fact, shows an interesting fairly continuous contraction clearly evidenced by the shortening of about $1 \mathrm{~cm}$ from BEMI (Bellamira) to TANQ (Tanque), from TANQ to MOPG (Ministerio de Obras Publicas) and about $1.5 \mathrm{~cm}$ from PATI (Patio) to TANQ (Fig. 10); the fairly constant rate of contraction suggests a long-term constant dynamic controlling this side of the volcano, especially on its eastern to southeastern flank, due to the stability of the distances between BEMI, PATI and MOPG stations. A similar behavior appears on the northern flank of the volcano, affecting the distances from PATI to RANC (Ranchito) and VSMG (Volcano San Miguel summit), while the PATIBEMI distance seems to show only a very slight and less constant contraction. In any case, on most of the time series a marked contraction is visible around the 12 February ash emission and, on all distance variations, another contraction marks the 12 April one. Longer time series in the future will evidence and eventually confirm this kind of almost linear deformation.

Distances between the stations located on the summit part (Fig. 11) seem to evidence a slight deflation/inflation behavior encompassing the tremor increase and ash emission of 12 February and 12 April. In particular, a deflation accompanied the tremor increase in February and a subsequent inflation affected the summit area after the ash emission until about the first half of March 2014; then a new slight inflation started, culminating roughly with the new 12 April ash emission. This deformation is very local, affecting the summit part of the volcano and is confirmed by the opposite behavior of the radial distances, involving the same stations at lower altitudes and not lying on opposite sides of the volcano. Distances from SJOR (San Jorge town hall) to LACA and from VSMG to BEMI, in fact, extend before the 12 February ash emission and contract immediately after. The VSMGBEMI distance also evidences another significant extension episode, roughly corresponding to a temporary increase of tremor amplitude recorded in mid-March (see Fig. 5) with a following contraction culminating with the 12 April ash emission. It is interesting to note the significant increase of the distances from VSMG and RANC to LACA following the 12 February ash emission, indicating a relative motion of LACA and confirmed by the shortening of its distance to SJOR.

Looking at the baselines radially crossing the volcano (Fig. 12), it would be possible to infer the overall largescale behavior of the edifice. It is interesting to note that the $\mathrm{N}-\mathrm{S}$ distance, i.e., PATI-VMIG, is more sensitive to the volcanic dynamics with respect to the E-W SJOR-BEMI and SJOR-MOPG ones. Indeed, it shows the same deflation/inflation cycle around the 12 February ash emission and another contraction episode in mid-March, with a specular behavior with respect to the VSMG-BEMI distance (see 


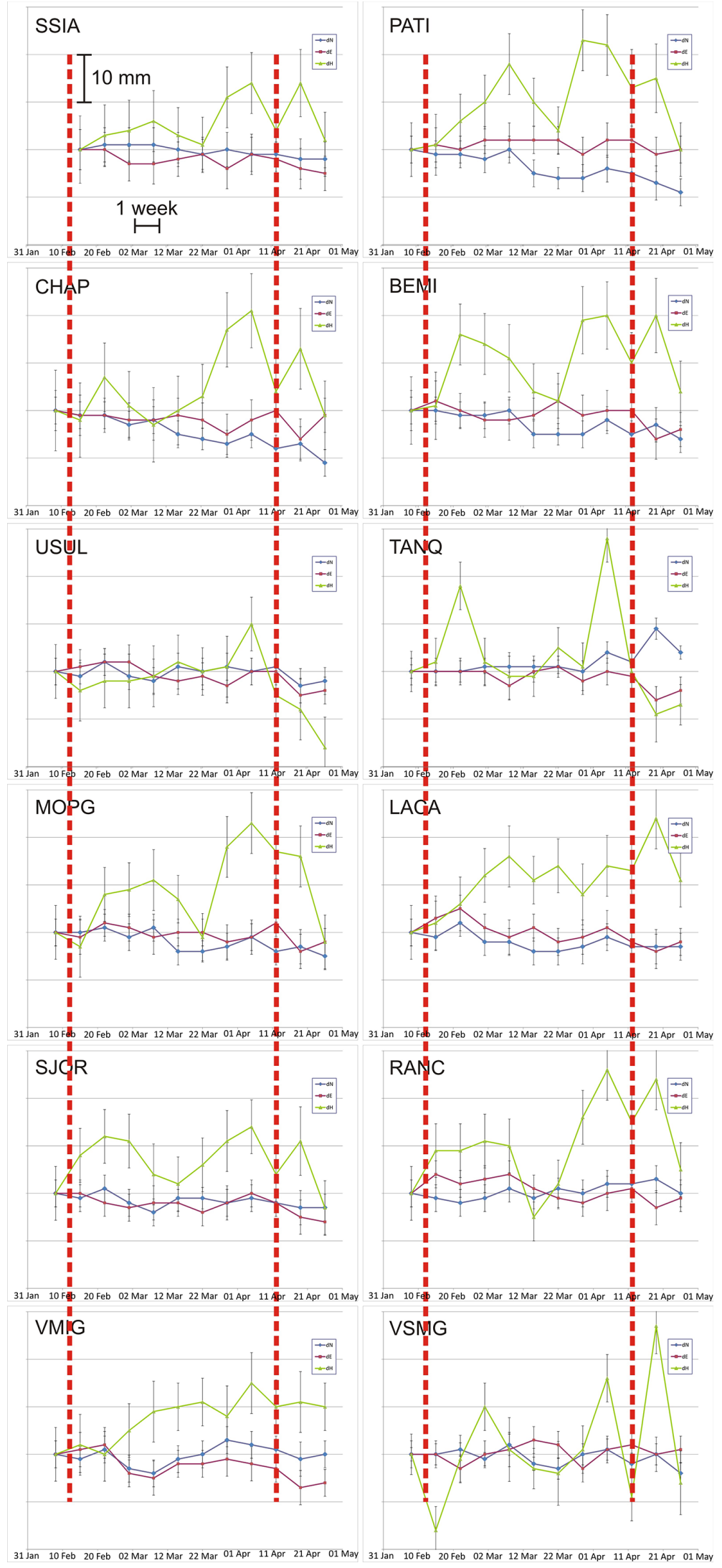

Figure 9. Weekly time series of the three components of displacements at the GPS stations. Vertical dashed lines indicate the occurrence of small ash emissions at the San Miguel volcano. 


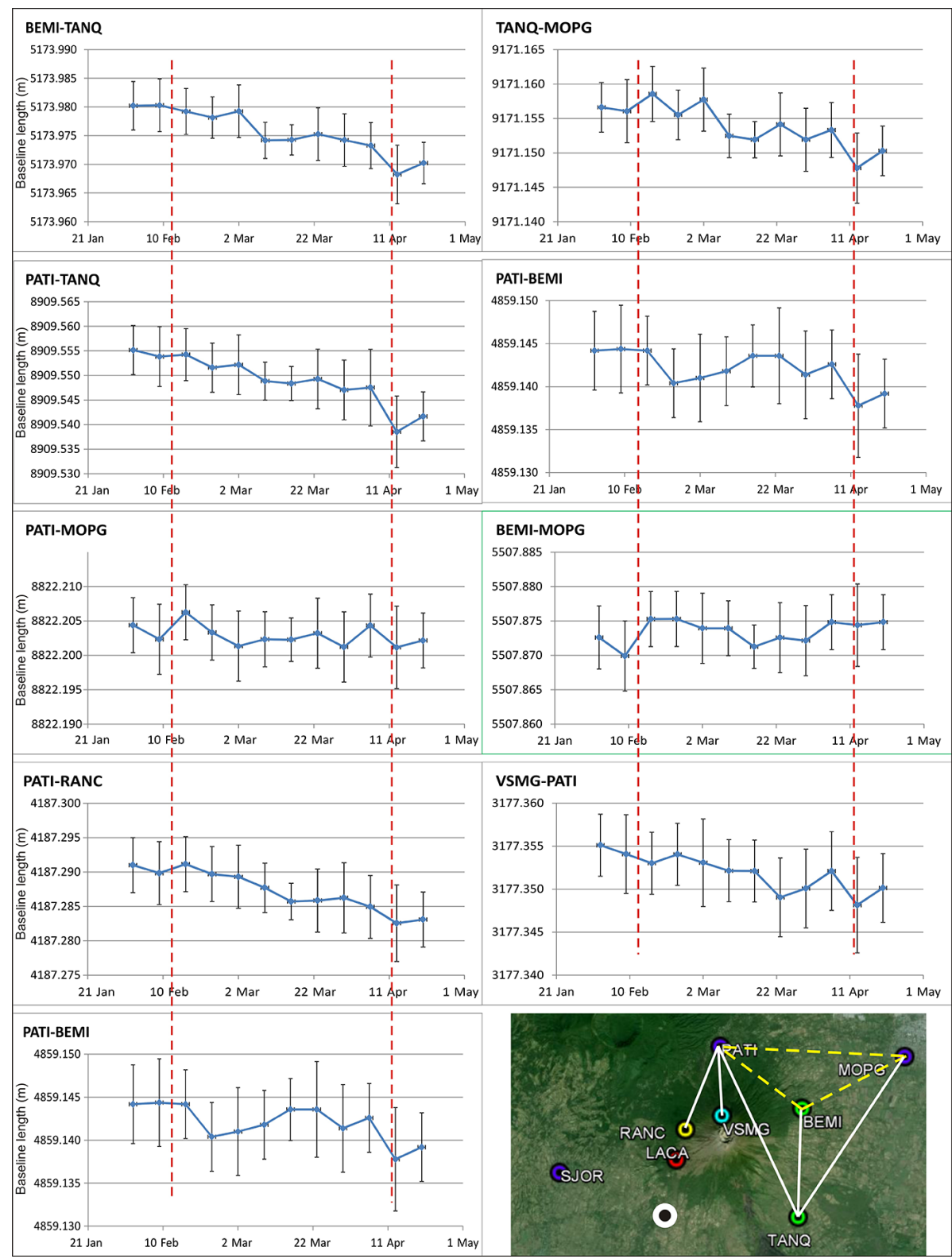

Figure 10. Baseline length variations (meters) between stations lying on the eastern and northern sides of the volcano. The map shows the location and kinematics of the baselines: white solid lines indicate contracting distances, yellow dashed lines indicate the baselines showing no significant variations.

Fig. 11). Only E-W distances involving summit stations can be sensitive to the volcanic dynamics, as evidenced by the LACA-BEMI and RANC-BEMI ones, due to the same dynamics described in Fig. 11; they show inflation during the mid-March tremor increase, with an opposite behavior with respect to the N-S PATI-VMIG distance and a following long-term deflation leading to the 12 April ash emission.

Looking at the rest of the edifice (Fig. 13), the southern flank seems to be the most stable side of the volcano, showing no significant deformation during the monitored period, while the western flank evidences some fluctuations similar to those observed on the other long baselines of Fig. 12; in particular, the SJOR-VMIG distance shows a fluctuation accompanying the mid-March tremor increase, similar to what is observed, with higher amplitude on the RANC-BEMI and LACA-BEMI baselines crossing the edifice (Fig. 12). A significant variation following the 12 February ash emission, similar to what is observed in Fig. 11, is also visible. Here, a contraction affects the southwestern SJOR-VMIG baselines and an extensions affects the northeastern SJOR-PATI and PATI-LACA ones, confirming the motion of LACA and suggesting an extension of this deformation, with a decreasing 


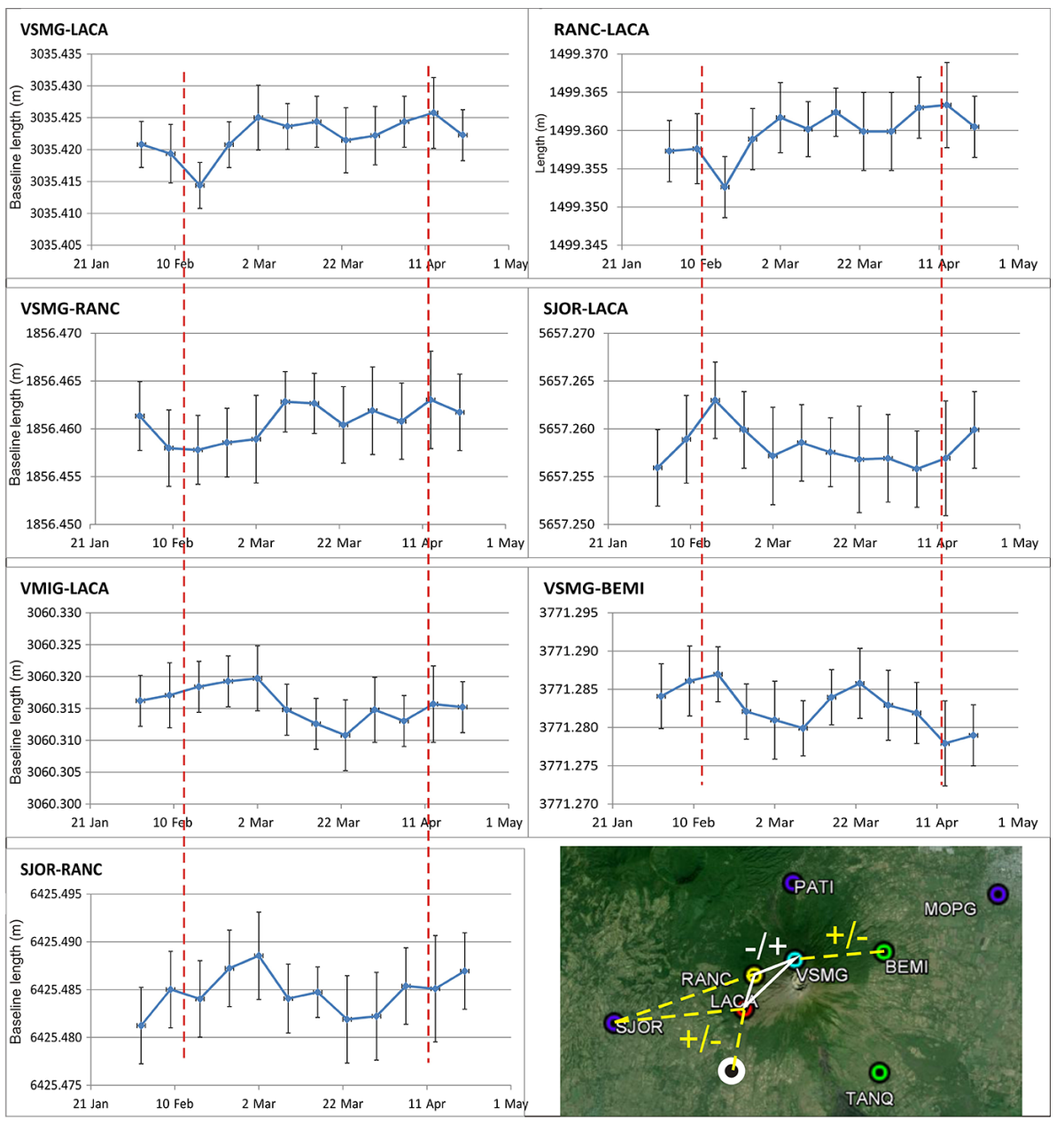

Figure 11. Baseline length variations (meters) evidencing the dynamics mainly affecting the summit part of the volcano. The map shows the location and kinematics of the baselines: when only the summit part extends (white solid lines), this produces contraction on the lower flanks (yellow dashed lines) and vice versa.

amplitude, on the southwestern flank down to SJOR, evidencing with a better accuracy the horizontal motion visible in Fig. 9. Coupling the information coming from the baselines variations visible in Figs. 11 and 13 and the uplift plotted in Fig. 9, we can infer that a local inflation affected the upper WSW flank of the volcano after the 12 February ash emission.

\section{Conclusions}

This work focuses on the international cooperation, prompted by the Ministerio de Medio Ambiente y Recursos Naturales of El Salvador and carried out with the Italian V-EMER team from the Istituto Nazionale di Geofisica e Vulcanologia to implement a multiparametric monitoring network for managing the crisis after the unrest of the San Miguel volcano. Particular emphasis is given here to the ground deformation network design, installation and data analyses.

The installation of a new ground deformation monitoring network by means of self-centering benchmarks can be considered a first permanent result, with 10 geodetic benchmarks installed on and around the volcano, available to deal with future threats and for studying and monitoring this poorly known but hazardous volcano.

In addition, data analyses presented here provide very important and new information on the ground deformation affecting the San Miguel volcano. Even if data inversion and modeling was not possible due to the slight deformation, we were able to detect and define different sectors of the edifice affected by diverse ground deformation patterns. We can summarize all the observations of ground deformation in the following points, defining some characteristic features that can be useful to appropriately plan and interpret future monitoring of the volcano. 


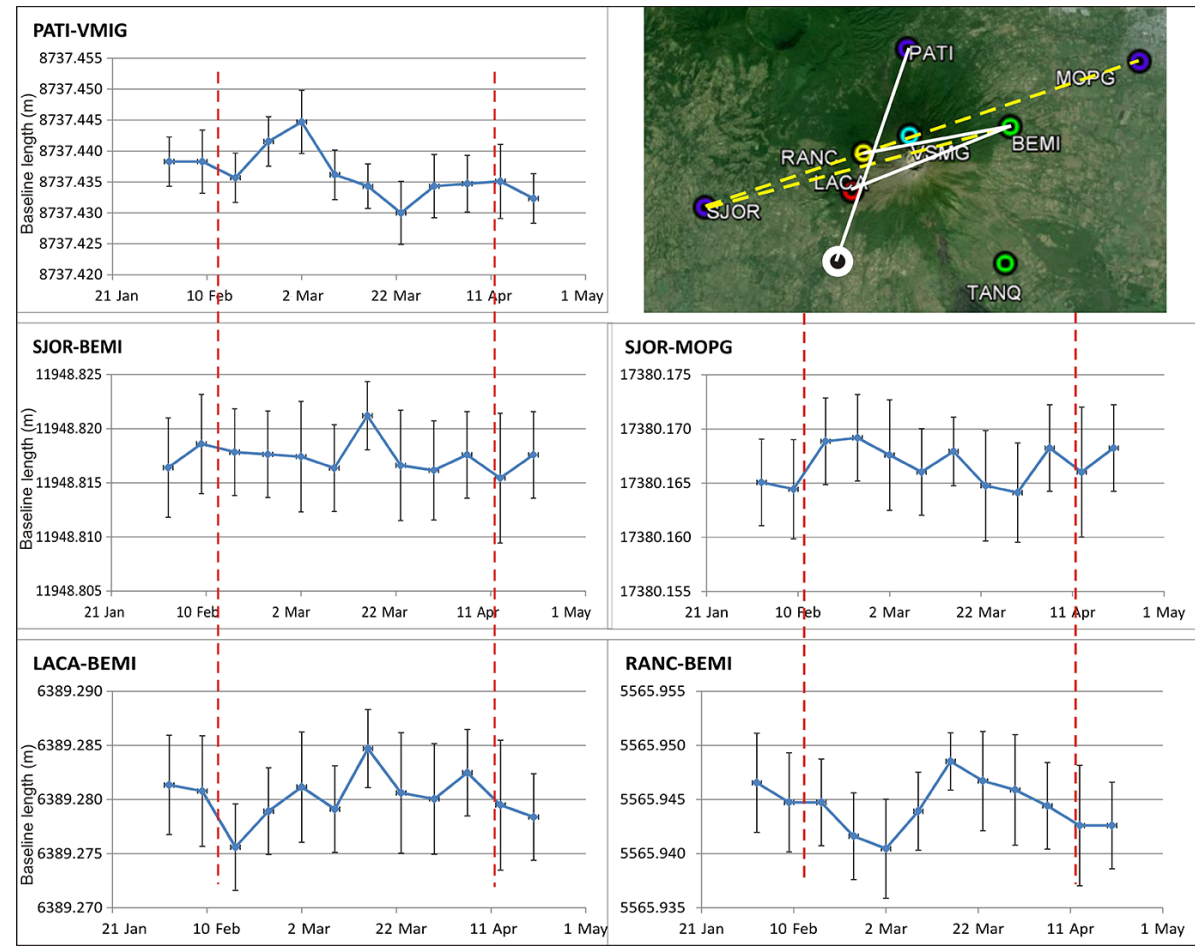

Figure 12. Variations of long length baselines (meters) crossing the volcano. The map shows the location and kinematics of the baselines: white solid lines indicate baselines showing significant fluctuations, yellow dashed lines indicate baselines showing no deformation.

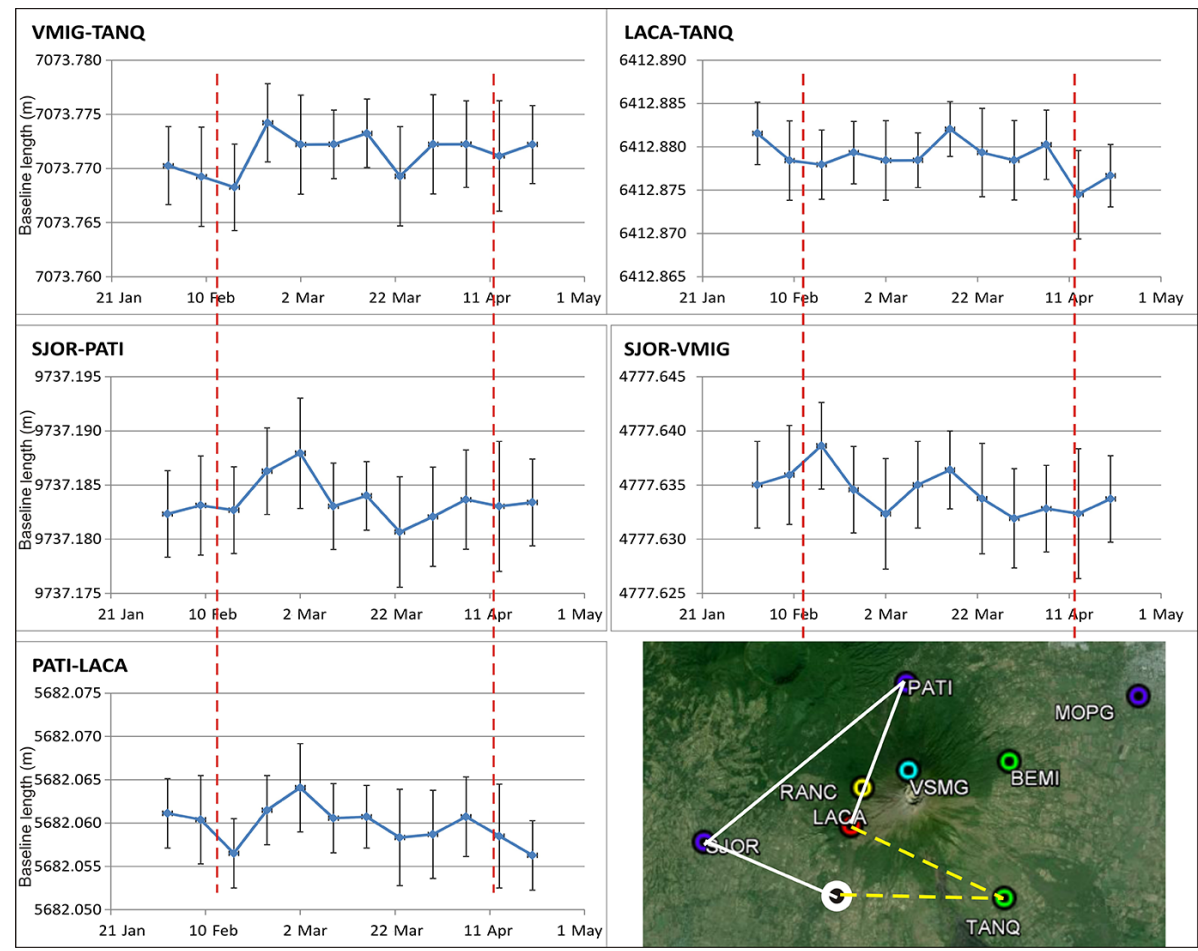

Figure 13. Baseline length variations (meters) between stations lying on the southern and western sides of the volcano. The map shows the location and kinematics of the baselines: white solid lines indicate fluctuating distances, yellow dashed lines indicate the baselines showing no significant variations. 
1. A general and continuous contraction affects the N$\mathrm{S}$ baselines on the southeastern and northern sides of the San Miguel volcano, indicating a long-term contraction, probably imputable to a deflation of the edifice that, for some tectonic/structural reasons, particularly affects this sector of the edifice. A different sensitivity of different sectors of a volcano to the ground deformation has been observed also, for example, at Mt. Etna (Bonforte et al., 2008, 2011) and is related to the volcanotectonic setting that allows different sides of the edifice to respond differently to different dynamics. A continuous deflation of the volcano is also compatible with the geochemical observations that evidenced a higher degassing (with respect to the background level before the eruption, Granieri et al., 2015) during the whole investigated period.

2. The stations at highest altitudes are the most sensitive to the dynamics accompanying the eruptive activity, indicating that the magma dynamics during the investigated period mainly involved the upper part of the feeding system.
3. Long E-W baselines are fairly stable, while long N$\mathrm{S}$ ones show some fluctuations; the latter, as well as the short $\mathrm{E}-\mathrm{W}$ ones involving summit stations, show longterm variations that seem related to the tremor amplitude fluctuations and volcanic activity.

All these ground deformation features are in good agreement with the observed seismic and geochemical observations. Even if GPS displacements are not strong enough to be inverted for modeling and constraining a ground deformation source, all independent observations (geodetic, seismic and geochemical) seem to converge in defining a depressurizing (degassing) batch of magma located beneath the upper northern slope of the volcano. On a positive note, productive teamwork has begun with this international cooperation and local personnel have been trained in network installation and data management. 


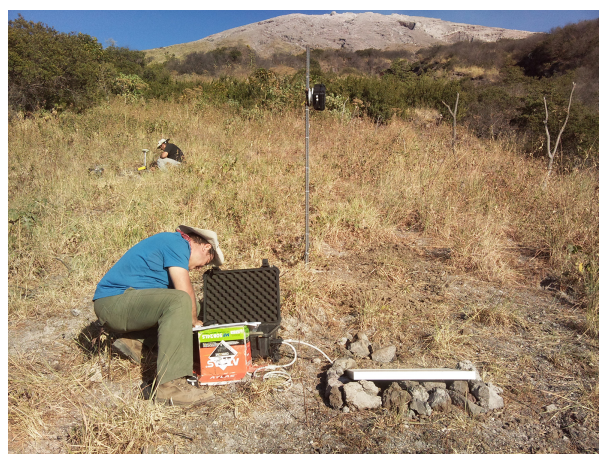

Figure A1. Ranchito multiparametric station (RANC). Seismic station in the foreground; the radiometer is installed on the pole in the image center; the GPS station is visible a few meters further up.

\section{Appendix A: Field operations for the emergency}

On January 2014, a partnership made up of an Italian team (named V-EMER) from INGV and a local team from MARN was organized to improve the geochemical and geophysical multiparametric monitoring system after the 29 December 2014 eruption. The joint team installed on and around the volcano a mobile multiparametric network that was shipped from Italy. It consisted of geochemical automatic stations, infrasound sensors, seismic broadband stations, radiometric sensors for measuring the gas plume temperature, multigas and a UV-scanner (for measuring $\mathrm{CO}_{2} / \mathrm{SO}_{2}$ and $\mathrm{SO}_{2}$ flux, respectively), FTIR to observe $\mathrm{SO}_{2} / \mathrm{HCl}$ and $\mathrm{SO}_{2} / \mathrm{HF}$ (Granieri et al., 2015), GPS stations as well as a thermal camera to monitor the northern side of the volcano which, up to the time of writing, still provides real-time monitoring of the volcanic activity.

The installed ground deformation network was designed to cover the entire volcano from the lowest to the highest possible altitude. A detailed and optimal distribution of measuring points was required and designed to monitor not only the central part of the volcano but also its flanks due to the possibility of even more dangerous flank intrusions and/or slope stability. To simplify the logistics for the quickest installation and for security reasons, some GPS sensors, where possible, were colocated with already existing geophysi$\mathrm{cal} /$ geochemical stations (seismic, infrasound, gas plume and radiometric, example in Fig. A1).

The geodetic network consisted of 10 self-centering benchmarks of the same type usually installed on Mt. Etna in Italy (Puglisi and Bonforte, 2004; Bonforte and Puglisi, 2006). These benchmarks allow rapid installation and setup of the instrumentation and have a minimum impact on environment; the minimum impact also allows the benchmark to be easily hidden and this reduces the chance of it being damaged and vandalized. The benchmarks consist of brass cylinders that are permanently installed in solid outcrops (Fig. A2) or stable reinforced concrete structures (Fig. A2b) by simply

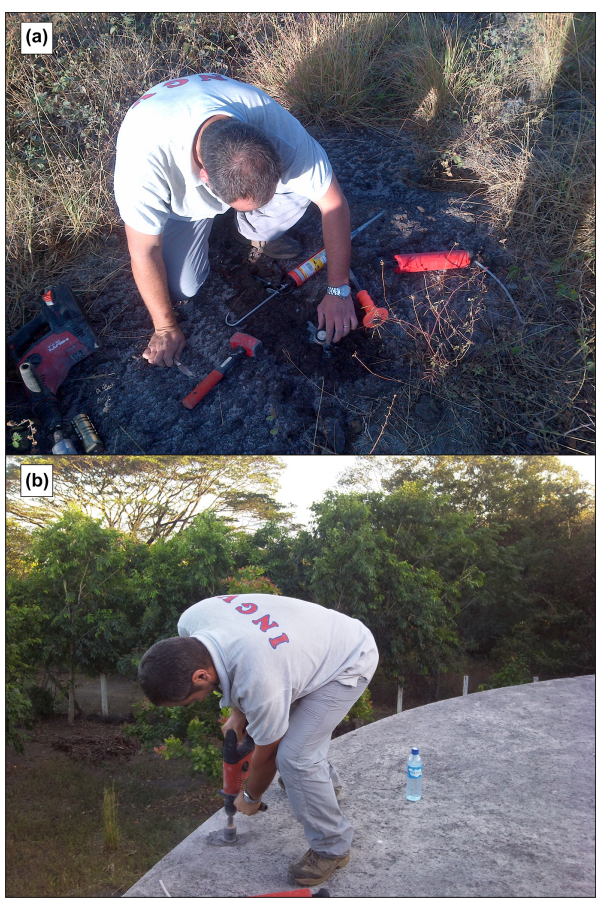

Figure A2. Installation of (a) Lacayo benchmark (LACA) on rocky lava outcrop and (b) Tanque benchmark (TANQ) on existing reinforced concrete structure.

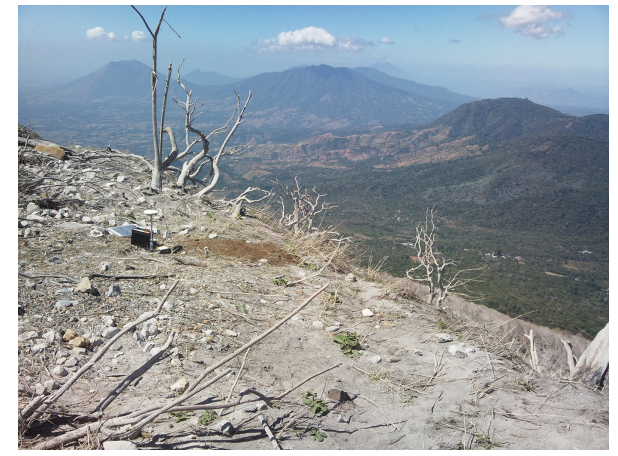

Figure A3. Volcano San Miguel summit GPS station (VSMG), installed on the upper northern flank of the volcano, made by a reinforced concrete cube buried in the pyroclastic material, where the self-centering benchmark was anchored.

drilling a $5 \mathrm{~cm}$-wide hole and accurately fixing them with resin epoxy. Only for the highest VSMG benchmark, a cubic $(50 \mathrm{~cm}$ sides) concrete block was buried in the pyroclastic material on the highest northern flank of the volcano (Fig. A3).

A screwed brass cap is usually closed and protects the benchmark when not in use. The internal part of the cylinders are designed to perfectly match, without any movement, the bottom of the geodetic pins that are screwed into them during the measurements. For this setup, $450 \mathrm{~mm}$-long aluminum pins were brought from Italy. The GPS antenna is 
then directly placed at the top of the vertical pin; the standard length and fixed coupling between the benchmarks and the removable pins prevent any setup error (Fig. A4). This type of benchmark enables setting up the station in less than a minute and even by personnel without any geodetic expertise. All geodetic benchmarks on and around Chaparrastique volcano were installed in 2 days, on 29 and 30 January. In order to start data acquisition as soon as possible due to the very quick resin stabilization, helped by the high environmental temperatures, it was possible to set up all the GPS equipment on the new benchmarks on 30 January, just after the last benchmark installations.

The final configuration of the multiparametric network installed by the joint international team is reported in Fig. 6. The GPS instrumentation comprised 10 Trimble dualfrequency receivers, model 4700 , equipped with 4 Trimble Zephyr and 6 Leica AX1202GG antennas. All stations were powered with $40 \mathrm{Ah}$ batteries and $20 \mathrm{~W}$ photovoltaic modules. Data were collected as daily files with a 30 s sampling interval.

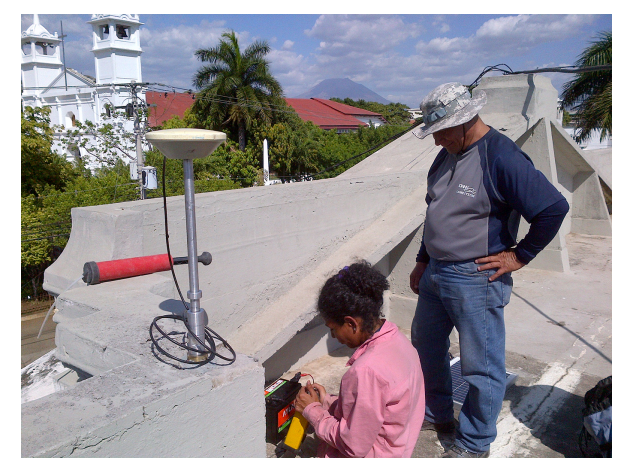

Figure A4. Close-up of the self-centering mount at the Usulutan site and training of the MARN personnel in the field.

Local personnel were also trained how to manage, program, maintain and process the collected data to ensure the maximum efficiency and local autonomy in managing the ongoing crisis. 
Author contributions. All authors participated in the fieldwork to install the multiparametric network and set up the instrumentation; in particular, Alessandro Bonforte was responsible for the ground deformation network and Salvatore Rapisarda for the seismic one. Piergiorgio Scarlato coordinated the team during the fieldwork. Eduardo Gutiérrez is an expert on the geology and tectonics of the area. Douglas Antonio Hernandez managed the GPS network and with Cecilia Polío and Louis Handal downloaded the data and maintained the instruments while installed in the field. Alessandro Bonforte performed the ground deformation analyses and coordinated the writing of the manuscript.

Acknowledgements. The authors wish to thank the Minister for the Environment of El Salvador H. Rosa as well as C. Kattan, S. Gresta, E. Privitera and P. Papale for making this cooperation possible and for funding the Italian mission; we wish to thank the Italian embassy in El Salvador and the Italian Ambassador T. Barucco for her personal interest. We are also grateful to all the INGV V-EMER group, technical staff of MARN and, in particular, to D. Escobar, F. Montalvo, L. Mixco, R. Castro, N. Galvez, G. Giuffrida, A. La Spina, M. Liuzzo, G. Salerno for the difficult field operations. Thanks are due to S. Conway for reviewing the manuscript for language and grammar. Thanks are also due to all the Italian colleagues who prepared all the equipment in Italy to be shipped for this cooperation.

Edited by: S. Tinti

Reviewed by: two anonymous referees

\section{References}

Altamimi, Z., Collilieux, X. and Métivier, L.: ITRF2008: an improved solution of the international terrestrial reference frame, J. Geodesy., 85, 457-473, doi:10.1007/s00190-011-0444-4, 2011.

Alvarado, D., DeMets, C., Tikoff, B., Hernández, D., Wawrzyniec, T., Pullinger, C., Rodríguez, M., and Tenorio C.: Forearc motion and deformation between El Salvador and Nicaragua: GPS, seismic, structural, and paleomagnetic observations, Lithosphere, 3, 3-21, doi:10.1130/L108.1, 2011.
Bonforte, A. and Guglielmino, F.: Transpressive strain on the Lipari-Vulcano volcanic complex and dynamics of the "La Fossa" cone (Aeolian Islands, Sicily) revealed by GPS surveys on a dense network, Tectonophysics, 457, 64-70, doi:10.1016/j.tecto.2008.05.016, 2008.

Bonforte, A. and Puglisi, G.: Dynamics of the eastern flank of Mt. Etna volcano (Italy) investigated by a dense GPS network, J. Volcanol. Geoth. Res., 153, 357-369, doi:10.1016/j.jvolgeores.2005.12.005, 2006.

Bonforte, A., Bonaccorso, A., Guglielmino, F., Palano, M., and Puglisi, G.: Feeding system and magma storage beneath Mt. Etna as revealed by recent inflation/deflation cycles, J. Geopys. Res., 113, B05406, doi:10.1029/2007JB005334, 2008.

Bonforte, A., Guglielmino, F., Coltelli, M., Ferretti, A., and Puglisi, G.: Structural assessment of Mount Etna volcano from Permanent Scatterers analysis, Geochem. Geophy. Geosy., 12, Q02002, doi:10.1029/2010GC003213, 2011.

Correa-Mora, F., DeMets, C., Alvarado, D., Turner, H. L., Mattioli, G., Hernandez, D., Pullinger, C., Rodriguez, M., and Tenorio, C.: GPS-derived coupling estimates for the Central America subduction zone and volcanic arc faults: El Salvador, Honduras and Nicaragua, Geophys. J. Int., 179, 1279-1291, doi:10.1111/j.1365-246X.2009.04371.x, 2009.

Escobar, D., Ferres, D., Pullinger, C., Delgado, H., Farraz, I., Alatorre, M., and Hurst, A.: Memoria Técnica de los Mapas de Escenarios de Amenaza Volcánica, Volcán de San Miguel o Chaparrastique, http://www.snet.gob.sv/Geologia/Vulcanologia/ memorias/mtVSM (last access: 9 March 2012), 2004.

Granieri, D., Salerno, G., Liuzzo, M., La Spina, A., Giuffrida, G., Caltabiano, T., Giudice, G., Gutierrez, E., Montalvo, F., Burton, M. R., and Papale, P.: Emission of gas and atmospheric dispersion of SO2 during the December 2013 eruption at San Miguel volcano (El Salvador, Central America). Geophys. Res. Lett., 42, 5847-5854, doi:10.1002/2015GL064660, 2015.

MARN: Cronología de Erupciones Volcán de San Miguel, Miguel, http://www.snet.gob.sv/ver/vulcanologia/monitoreo/historial+ eruptivo/?id_volcan=7, last access: January 2014.

Puglisi, G. and Bonforte, A.: Dynamics of Mount Etna Volcano inferred from static and kinematic GPS measurements, J. Geophys. Res., 109, B11404, doi:10.1029/2003JB002878, 2004.

Schiek, C.: Characterizing the deformation of reservoirs using Radar, Interferometry, Gravity and Seismic Analysis, Dissertation, The University of Texas at El Paso, TX, USA, 2008. 